\title{
Future glucose-lowering drugs for type 2 diabetes
}

\author{
Clifford J Bailey, Abd A Tahrani, Anthony H Barnett
}

\section{Summary}

The multivariable and progressive natural history of type 2 diabetes limits the effectiveness of available glucoselowering drugs. Constraints imposed by comorbidities (notably cardiovascular disease and renal impairment) and the need to avoid hypoglycaemia, weight gain, and drug interactions further complicate the treatment process. These challenges have prompted the development of new formulations and delivery methods for existing drugs alongside research into novel pharmacological entities. Advances in incretin-based therapies include a miniature implantable osmotic pump to give continuous delivery of a glucagon-like peptide-1 receptor agonist for 6-12 months and onceweekly tablets of dipeptidyl peptidase- 4 inhibitors. Hybrid molecules that combine the properties of selected incretins and other peptides are at early stages of development, and proof of concept has been shown for small non-peptide molecules to activate glucagon-like peptide-1 receptors. Additional sodium-glucose co-transporter inhibitors are progressing in development as well as possible new insulin-releasing biological agents and small-molecule inhibitors of glucagon action. Adiponectin receptor agonists, selective peroxisome proliferator-activated receptor modulators, cellular glucocorticoid inhibitors, and analogues of fibroblast growth factor 21 are being considered as potential new approaches to glucose lowering. Compounds that can enhance insulin receptor and post-receptor signalling cascades or directly promote selected pathways of glucose metabolism have suggested opportunities for future treatments. However, pharmacological interventions that are able to restore normal $\beta$-cell function and $\beta$-cell mass, normalise insulin action, and fully correct glucose homoeostasis are a distant vision.

\section{Introduction}

A wealth of evidence from prospective and retrospective clinical studies supports the premise that early, effective, and sustained glycaemic control defers the onset of diabetes and reduces the severity of associated complications..$^{1-3}$ However, more than a third of all patients with diabetes do not achieve or maintain an appropriate glycaemic target. ${ }^{1,4}$ Although this situation is attributed partly to late diagnosis of diabetes, delayed introduction or insufficient escalation of treatment, or poor patient adherence, more efficacious and durable treatments are needed. Type 2 diabetes is usually the product of various genetic susceptibilities and environmental factors that interact to create a highly heterogeneous and progressive pathological changes against which existing treatments have substantial limitations. ${ }^{5}$ About half of all patients with type 2 diabetes require combinations of two or more differently acting non-insulin glucose-lowering drugs and about a third of patients will require insulin. ${ }^{6}$ Moreover, the complications and comorbidities (eg, cardiovascular disease and renal impairment) that typically accompany advanced states of insulin resistance and pancreatic $\beta$-cell dysfunction restrict the choice of available treatments.

This update of a previous narrative Review in The Lancet in $2011^{7}$ uses the same literature search procedure to carry the review forward to June, 2015. Emphasis is given to clinical studies of agents that are advanced in development and preclinical experimentation that explores potential new therapeutic mechanisms for diabetes. The main sites of action of present and possible future glucose-lowering treatments are summarised in figure 1 and key features of the modes of action of potential future therapies are summarised in table $1 .{ }^{8}$

\section{Pancreatic $\beta$-cell function Overview}

Interventions with lasting efficacy are needed to prevent and reverse the progressive reduction in pancreatic $\beta$-cell function and $\beta$-cell mass in patients with type 2 diabetes. ${ }^{9}$ Compounds acting at the level of the $\beta$ cell currently under investigation include the small molecule insulin releasers, glucokinase activators, fatty acid receptor agonists, and imeglimin.

\section{Small molecule insulin releasers}

In addition to established initiators of insulin secretion (sulfonylureas and meglitinides), many compounds are known to improve $\beta$-cell function in vitro. These small molecule insulin releasers include succinate esters, imidazolines, selective phosphodiesterase inhibitors, $\alpha-2$ adrenergic antagonists, and agents that close Kir6.2 potassium channels or open membrane calcium channels. However, the in-vivo effects of most of these compounds are too generalised to specifically target $\beta$ cells and few have progressed in development. ${ }^{10}$

\section{Glucokinase activators}

Activators of the glucose phosphorylating enzyme, glucokinase, increase both insulin secretion and hepatic glucose metabolism (figure 2). Phase 2 and phase 3 studies in patients with type 2 diabetes have shown modest glucose-lowering for 4-6 months, but efficacy quickly reduces thereafter. ${ }^{11}$ With stimulation of insulin secretion at low glucose concentrations, glucokinase activators are prone to cause hypoglycaemia. However, glucokinase is regulated differently in the liver to the $\beta$ cell, and attention is now focused on the development of liver-selective glucokinase activators. Accumulation of hepatic triglycerides often occurs during protracted
Lancet Diabetes Endocrinol 2016 School of Life and Health Sciences, Aston University, Birmingham, UK (Prof C) Bailey PhD); Department of Diabetes and Endocrinology, Heart of England NHS Foundation Trust, Birmingham, UK (A A Tahrani PhD, Prof A H Barnett MD); and Centre for Endocrinology, Diabetes and Metabolism, University of Birmingham, Birmingham, UK (Prof A H Barnett) Correspondence to: Prof Clifford J Bailey, School of Life and Health Sciences, Aston University, Birmingham B4 7ET, UK c.j.bailey@aston.ac.uk 


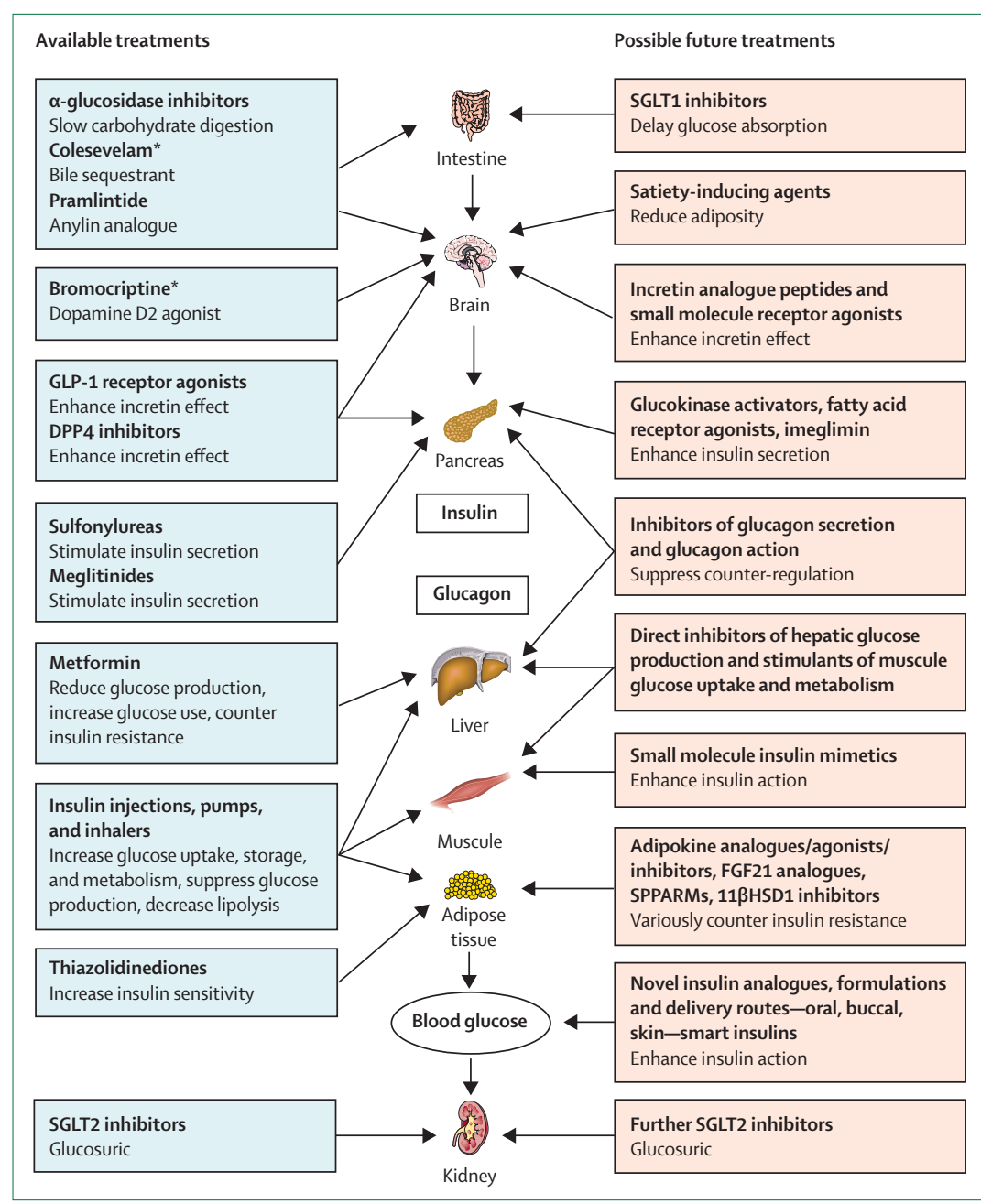

Figure 1: Intervention sites for glucose-lowering, showing available treatments and possible new treatments GLP1=glucagon-like peptide-1. DPP4=dipeptidyl-peptidase-4. SGLT2=sodium-glucose co-transporter 2 (also known as SLC5A2). SGLT1=sodium-glucose co-transporter 1 (also known as SLC5A1). FGF21=fibroblast growth factor 21. SPPARM=selective peroxisome proliferator-activated receptor modulator. $11 \beta H S D 1=11 \beta$-hydroxysteroid dehydrogenase $1 .{ }^{*}$ Not indicated for glucose-lowering in all countries.

glucokinase activation. This effect might be avoided with drugs that also enhance futile cycling in the liver, but long-term clinical efficacy remains to be established. ${ }^{12,13}$

\section{Fatty acid receptor agonists}

Several G-protein coupled receptors expressed by pancreatic $\beta$ cells are activated by fatty acids leading to enhanced insulin secretion-eg, GPR40 (also known as FFAR1) and GPR119. As receptors (not transporters), they do not mediate cellular entry of their agonists so they do not invoke the detrimental effects of chronic excess fatty acids on the metabolism and survival of $\beta$ cells. ${ }^{9}$ GPR40 agonists increase insulin secretion by increasing cytosolic calcium. A promising GPR40 agonist (TAK-875) was discontinued because of hepatic side-effects, but other GPR40 agonists continue in development..$^{14}$
GPR119 agonists activate adenylate cyclase, increasing cyclic adenosine monophosphate and potentiating nutrient-induced insulin secretion in a similar manner to glucagon-like peptide-1 (GLP1). ${ }^{15}$ Both GPR40 and GPR119 are expressed by enteroendocrine pancreatic cells and other cells, K cells, L cells, and I cells, and synthetic agonists for these receptors can increase the secretion of glucose-dependent insulinotropic peptide (also known as gastric inhibitory polypeptide, GIP), GLP1, peptide YY (PYY), and cholecystokinin, potentially enhancing the incretin and satiety effects of these hormones. GPR40 and GPR119 receptors are also expressed by pancreatic $\alpha$ cells and agonists might increase glucagon secretion. ${ }^{16}$

Another long-chain fatty acid receptor, GPR120 (also known as FFAR4), expressed mainly by adipose tissue, promotes adipogenesis. Small molecule agonists of this receptor improve glucose homoeostasis by increasing insulin sensitivity and reducing ectopic fat in preclinical studies. ${ }^{17}$

\section{Imeglimin}

Imeglimin is a triazine derivative that enhances glucoseinduced insulin secretion, especially the first phase, and improved glycaemic control during phase 2 studies in type 2 diabetes. It seems to change cellular energetics, in part through closure of mitochondrial permeability transition pores, which can also improve peripheral insulin sensitivity and reduce hepatic gluconeogenesis. ${ }^{18}$

\section{Incretin-based therapies Overview}

Hormonal signals from the alimentary tract continue to provide important therapeutic templates for type 2 diabetes. The main incretin hormone, GLP1, has been successfully exploited in this respect by changing the molecule to avoid rapid inactivation by the enzyme dipeptidyl-peptidase-4 (DPP4) or by inhibiting DPP4. ${ }^{4}$

\section{GLP1 receptor agonists}

Injectable GLP1 receptor agonists (exenatide, liraglutide, lixisenatide, albiglutide, and dulaglutide) potentiate nutrient-induced insulin release, suppress excess glucagon secretion, delay gastric emptying, and exert satiety effects that assist with weight control. Although these agents have increased $\beta$-cell mass in animal studies, ${ }^{19}$ this finding has yet to be clearly shown in human beings with type 2 diabetes. To avoid daily or weekly injections, a matchstick-sized subcutaneously implanted miniature osmotic pump has been developed for continuous delivery of up to $80 \mu \mathrm{g}$ /day of exenatide. In an extended phase 2 study, implants delivering doses of $40 \mu \mathrm{g} /$ day or more of this GLP1 receptor agonist for 48 weeks in patients with type 2 diabetes reduced $\mathrm{HbA}_{1 \mathrm{c}}$ (by $0.93-1.42 \%$; $10-15 \mathrm{mmol} / \mathrm{mol}$ ) from a baseline of about $8 \%(64 \mathrm{mmol} / \mathrm{mol}$ ) and weight (by $3 \cdot 0-4.2 \mathrm{~kg}$ ) from a baseline of $93 \mathrm{~kg}$. Initial dose-related nausea 


\begin{tabular}{|c|c|c|c|c|}
\hline & Mechanism of action & Glucose-lowering effect & $\begin{array}{l}\text { Development } \\
\text { status }\end{array}$ & Comments \\
\hline Glucokinase activators & $\begin{array}{l}\text { Increase glucokinase activity in } \\
\text { pancreatic islets and liver }\end{array}$ & $\begin{array}{l}\text { Increase insulin secretion and } \\
\text { hepatic glucose uptake }\end{array}$ & Phase 3 & $\begin{array}{l}\text { Challenges of hypoglycaemia and } \\
\text { durability }\end{array}$ \\
\hline $\begin{array}{l}\text { GPR40 (also known as FFAR1) and GPR119 } \\
\text { agonists }\end{array}$ & $\begin{array}{l}\text { Activates fatty acid receptors in } \\
\text { pancreatic islets and gut }\end{array}$ & $\begin{array}{l}\text { Increase insulin secretion and } \\
\text { enteroendocrine L-cell incretin } \\
\text { secretion }\end{array}$ & Phase 1-3 & $\begin{array}{l}\text { TAK-875 (GPR40 agonist) discontinued in } \\
\text { phase } 3\end{array}$ \\
\hline Imeglimin & Close mitochondrial transition pores & $\begin{array}{l}\text { Increases insulin secretion and } \\
\text { decreases gluconeogenesis }\end{array}$ & Phase 3 & \\
\hline Exenatide implantable osmotic pump & GLP1 receptor agonist & Mimics effects of GLP1 & Phase 3 & Active for 6-12 months \\
\hline Oral and subcutaneous semaglutide & GLP1 receptor agonist & Mimic effects of GLP1 & Phase 2-3 & $\begin{array}{l}\text { Oral drug has similar efficacy to } \\
\text { subcutaneous injection }\end{array}$ \\
\hline Non-peptide GLP1 receptor agonists & GLP1 receptor agonist & Mimic effects of GLP1 & Preclinical & Proof of concept \\
\hline Omarigliptin (once-weekly) & DPP4 inhibitor & $\begin{array}{l}\text { Increase endogenous incretin } \\
\text { action }\end{array}$ & Phase 3 & Efficacy similar to sitagliptin \\
\hline TGR5 (also known as GPBAR1) agonists & Stimulate bile acid receptors in ileum & Increase L-cell incretin secretion & Preclinical & Preliminary observations \\
\hline $\begin{array}{l}\text { Fixed-ratio combinations; GLP1 receptor agonists } \\
\text { with insulin }\end{array}$ & GLP1 receptor agonist and basal insulin & $\begin{array}{l}\text { Mimic effects of GLP1 and } \\
\text { insulin at same time }\end{array}$ & Phase 3 & $\begin{array}{l}\text { Insulin degludec and liraglutide } \\
\text { combination was recently approved and } \\
\text { insulin glargine and lixisenatide } \\
\text { combination is in development }\end{array}$ \\
\hline Hybrid and chimeric designer peptides & $\begin{array}{l}\text { Agonism or partial antagonism of } \\
\text { selected peptides }\end{array}$ & $\begin{array}{l}\text { Mimic effects of selected } \\
\text { incretins and other peptides }\end{array}$ & Preclinical & Proof of concept \\
\hline Glucagon receptor antagonists & Decrease glucagon action & Decrease hepatic glucose output & $\begin{array}{l}\text { Preclinical to } \\
\text { phase } 2\end{array}$ & $\begin{array}{l}\text { Several drugs identified in preclinical } \\
\text { studies, restricted clinical progression }\end{array}$ \\
\hline Insulin receptor signalling potentiators & $\begin{array}{l}\text { Prolong Tyr phosphorylation of insulin } \\
\text { receptor B-subunit }\end{array}$ & Increase insulin action & Preclinical & $\begin{array}{l}\text { Proof of concept-eg, PTP1B (also known } \\
\text { as PTPN1) inhibitors and vanadium salts }\end{array}$ \\
\hline SGLT1 and 2 inhibitors & $\begin{array}{l}\text { Selectively decrease SGLT1 (also known } \\
\text { as SLC5A1) and SGLT2 (also known as } \\
\text { SLC5A2) activity in gut and kidney }\end{array}$ & $\begin{array}{l}\text { Increase renal glucose } \\
\text { elimination; delays gut glucose } \\
\text { absorption; changes incretin } \\
\text { secretion }\end{array}$ & Phase 2-3 & Efficacy shown in initial clinical studies \\
\hline Non-peptide adiponectin receptor agonists & Adiponectin R1/R2 agonists & Increase insulin action & Preclinical & Proof of concept \\
\hline FGF21 analogues & FGF21 receptor agonists & $\begin{array}{l}\text { Increase insulin sensitivity and } \\
\text { improves lipid profile }\end{array}$ & Phase 1 & Might act partly through adiponectin \\
\hline GPR120 (also known as FFAR4) & $\begin{array}{l}\text { Activates fatty acid receptors in } \\
\text { adipose and other tissues }\end{array}$ & $\begin{array}{l}\text { Increases insulin sensitivity and } \\
\text { adipogenesis }\end{array}$ & Preclinical & Proof of concept \\
\hline $\begin{array}{l}\text { Selective peroxisome proliferator-activated } \\
\text { receptor modulators }\end{array}$ & $\begin{array}{l}\text { Selective peroxisome proliferator- } \\
\text { activated receptor alpha, gamma, and } \\
\text { delta agonists }\end{array}$ & $\begin{array}{l}\text { Increase insulin sensitivity, } \\
\text { adipogenesis or lipid profile, and } \\
\text { islet } \beta \text {-cell viability }\end{array}$ & Phase 1-2 & $\begin{array}{l}\text { Opportunity to selectively enhance efficacy } \\
\text { and reduce unwanted effects }\end{array}$ \\
\hline $11 \beta$ hydroxysteroid dehydrogenase- 1 inhibitors & $\begin{array}{l}\text { Inhibit } 11 \beta \text { hydroxysteroid } \\
\text { dehydrogenase- } 1 \text { conversion of } \\
\text { cortisone to cortisol in liver and } \\
\text { adipose tissue }\end{array}$ & $\begin{array}{l}\text { Increase insulin sensitivity and } \\
\text { improves lipid profile }\end{array}$ & Phase 1-2 & $\begin{array}{l}\text { Challenge to prevent compensatory rise in } \\
\text { concentration of adrenocorticotropic } \\
\text { hormone }\end{array}$ \\
\hline Fructose- 1,6 bisphosphatase inhibitors & $\begin{array}{l}\text { Increase fructose- } 1,6 \text { bisphosphatase } \\
\text { activity }\end{array}$ & Decrease hepatic glucose output & Phase 2 & Initial clinical studies show efficacy \\
\hline Adenosine monophosphate kinase activators & $\begin{array}{l}\text { Increase adenosine monophosphate } \\
\text { kinase cellular effects on nutrient } \\
\text { metabolism }\end{array}$ & $\begin{array}{l}\text { Increase glucose uptake and } \\
\text { metabolism }\end{array}$ & Preclinical & Proof of concept \\
\hline
\end{tabular}

(mostly transient) was reported by about a third of participants and antibodies were detected in up to $10 \%$ of patients but did not seem to impair efficacy of exenatide. ${ }^{20}$ This therapy is in phase 3 of development.

Another approach to avoid injections is an oral tablet formulation of the GLP1 receptor agonist semaglutide. This peptide is in phase 3 trials, including one already completed trial (NCT02054897), as a once-weekly subcutaneous injection. The oral formulation is suggested to be equally effective. ${ }^{21}$ Studies in mice have shown that GLP1 receptor agonists can also be delivered by bioencapsulation in chloroplasts. ${ }^{22}$ Several nonpeptide small molecule GLP1 receptor agonists have been characterised in preclinical studies, but clinical efficacy has yet to be reported. ${ }^{23}$

\section{Dipeptidyl-peptidase-4 inhibitors}

DPP4 inhibitors (eg, sitagliptin, vildagliptin, saxagliptin, linagliptin, and alogliptin) are once-daily (or twice-daily for vildagliptin) oral drugs that enhance the effects of 
endogenous incretins by prolonging their circulating half-lives. Because the side-effects of these drugs have been minimal to-date, long-acting DPP4 inhibitors have been investigated. ${ }^{24}$ In the most advanced stage of development, omarigliptin has shown similar efficacy and tolerability as sitagliptin in phase 3 clinical studies. ${ }^{25}$

\section{TGR5 agonists}

The bile acid sequestrant colesevelam, which is indicated for use as a glucose-lowering drug in some countries, raises the possibility that carriage of bile acids more distally along the ileum could activate the TGR5 (also known as GPBAR1) bile acid receptors on L cells and enhance GLP1 secretion. Preliminary studies are investigating whether poorly absorbed TGR5 agonists can act distally along the intestinal tract to enhance GLP1 secretion..$^{26}$

\section{Peptide combinations}

A mix of two differently acting peptides in the same injection became a therapeutic reality with the introduction of IDegLira, a fixed-ratio combination of liraglutide with insulin degludec (ratio of $1.8 \mathrm{mg}$ of liraglutide to 50 units of insulin degludec). This combination is titrated in a similar manner to insulin, and during a 1-year prospective randomised phase 3

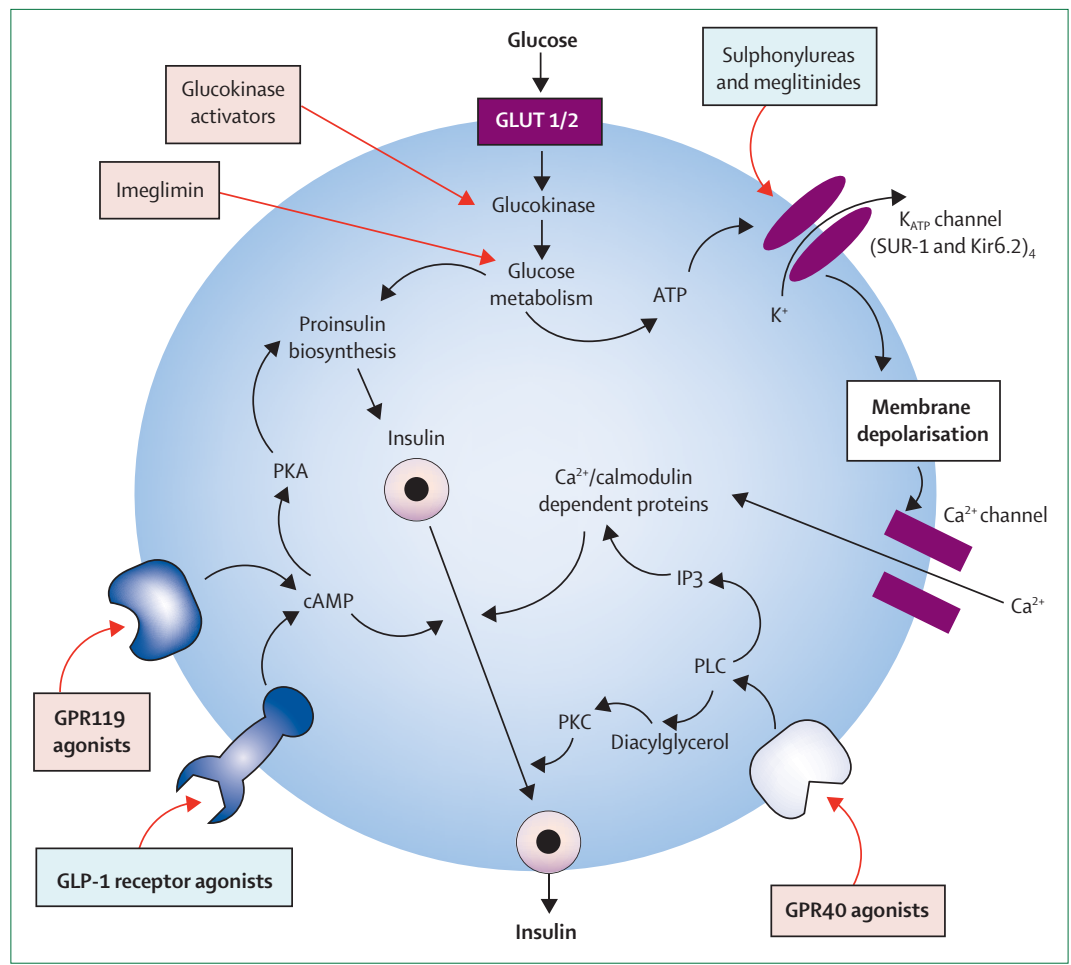

Figure 2: Pancreatic $\beta$ cell showing cellular mechanisms of insulin-releasing drugs ${ }^{8}$ Blue boxes=approved drugs. Pink boxes=drugs under investigation. ATP=adenosine triphosphate. $c A M P=c y c l i c$ adenosine monophosphate. GLUT=glucose transporter isoform. GLP1=glucagon-like peptide-1. GPR40=Gprotein-coupled receptor 40 (also known as FFAR1). GPR119=G-protein-coupled receptor 119. IP3=inositol trisphosphate. PLC=phospholipase C. $\mathrm{K}_{\mathrm{ATP}}=$ ATP-sensitive potassium channel. Kir=inwardly rectifying potassium channel. PKA=protein kinase $A$. PKC=protein kinase $C$. SUR=sulfonylurea receptor. trial $^{27}$ in patients who had insulin-naive type 2 diabetes, once-daily subcutaneous injection of IDegLira reduced $\mathrm{HbA}_{1 \mathrm{c}}$ by $1.84 \%(20 \cdot 2 \mathrm{mmol} / \mathrm{mol})$ compared with $1.40 \%$ $(15 \cdot 3 \mathrm{mmol} / \mathrm{mol})$ for insulin degludec alone and $1 \cdot 21 \%$ $(13.2 \mathrm{mmol} / \mathrm{mol}$ ) for liraglutide alone (each $\mathrm{p}<0.0001$ versus IDegLira). The combination achieved this effect with a lower insulin dose ( 39 units) than insulin degludec alone (62 units; $p<0 \cdot 0001$ ), and avoided weight gain in patients $(\mathrm{p}<0.0001$ between each treatment group). Preliminary data from a phase 2 study indicate that a fixed-ratio combination of lixisenatide and insulin glargine (Lixilan: ratio $50 \mu \mathrm{g}$ of lixisenatide to 100 units of glargine) has similar efficacy in patients who had insulinnaive type 2 diabetes. ${ }^{28}$

Preclinical and clinical studies have also explored the use of hybrid peptides in which two or more peptides are linked together to form a single molecule. ${ }^{29}$ These hybrids have mostly included combinations of GLP1 with glucagon, GIP, or other intestinal peptides. ${ }^{30}$ Hybrid molecules provide an opportunity to combine the effects of various peptides that affect blood glucose, lipids, satiety, energy expenditure, and adiposity, such as incretins, glucagon receptor agonists or antagonists, oxyntomodulin, PYY, obestatin, and ghrelin antagonists. These agents can be customised with a selection of desired sequences to construct chimeric molecules that exploit particular epitopes and enable new therapeutic portfolios in a single molecule. ${ }^{31,32}$ For example, molecules with satiety-inducing, weight-lowering, and glucoselowering properties might reproduce the metabolic effects of bariatric surgery. ${ }^{7}$ Although substantial physicochemical constraints and potential immunological issues need to be addressed, multipurpose designer molecules offer a novel potential therapeutic prospect.

\section{Glucagon secretion and action}

Reduction of prandial (but not fasting) glucagon secretion by pancreatic $\alpha$ cells is an important action of GLP1 receptor agonists. Other inhibitors of glucagon secretion (eg, somatostatin analogues) have not been suitable for glucose-lowering in type 2 diabetes, mainly because of interference with the counter-regulatory response to hypoglycaemia, which is already defective in most patients. ${ }^{10}$

Despite many accounts in the medical literature of glucagon receptor antagonists over more than 20 years, ${ }^{33}$ few have progressed beyond initial clinical trials. ${ }^{34,35}$ Unwanted effects on liver function have been described with some glucagon receptor antagonists, and glucagon receptor antagonism could possibly cause compensatory hyperglucagonaemia and rebound hyperglycaemia if treatment is not maintained.

\section{Insulin action}

Insulin binds to the extracellular $\alpha$ subunits of the insulin receptor, changing their conformation. This effect in turn changes conformation of the $\beta$ subunits 
that extend into the cytosol, exposing tyrosine residues in the $\beta$ subunits. Phosphorylation of these residues enables the $\beta$ subunits to act as kinase enzymes, activating insulin receptor substrate (IRS) proteins that trigger the various post-receptor pathways responsible for the genomic and non-genomic actions of insulin. Thus, insulin resistance in patients with type 2 diabetes has many potential causes, many different presentations, and many possible sites for intervention (figure 3). ${ }^{5,7-9}$ However, the rate-limiting defect is almost never identified and the potential benefits gained by circumventing any one defect might be off set by disturbances elsewhere in the insulin-receptor-effector pathways. Moreover, the various post-receptor signalling pathways of insulin action interact with, and are partly shared by, many other cellular signalling pathways, creating a challenge for any therapeutic intervention to act selectively on insulin action without interfering with other cellular control processes. In view of these constraints, much research into insulin resistance has, unsurprisingly, not yet yielded a new drug.

Because of the complexity of insulin receptor binding, ${ }^{36}$ small (non-peptide) molecules are unlikely to be able to duplicate this act. However, a monoclonal antibody (XmetA) that exhibits high affinity binding to the insulin receptor at a different site to insulin initiated some of the effects of insulin in animal cells in vitro and improved glycaemic control in insulin resistant diabetic mice. ${ }^{37}$ This finding suggests that conformational changes to the $\alpha$ subunit of the insulin receptor that differ from those induced by insulin binding could be exploited to produce conformational changes in the $\beta$ subunit that will elicit therapeutically beneficial effects.

A fungal metabolite, demethylasterriquinone, which interacts directly with the cytosolic part of the insulin receptor $\beta$ subunit, can initiate IRS-1-mediated postreceptor pathways without needing insulin binding. Although demethylasterriquinone is not suited to clinical development, the metabolite's ability to control the hyperglycaemia in diabetic animals suggests an opportunity exists for small molecules to mimic the actions of insulin. ${ }^{38}$

Various drugs have been reported to potentiate insulininitiated tyrosine phosphorylation of the insulin receptor $\beta$ subunit, or prevent its tyrosine dephosphorylation by phosphatases. ${ }^{39}$ In particular, drugs directed against protein tyrosine phosphatase $1 \mathrm{~B}$ and more general phosphatase inhibitors, such as vanadium salts, have successfully treated hyperglycaemic animals and shown efficacy in clinical trials, but none has proved sufficiently selective or free of side-effects to proceed into routine clinical use. ${ }^{40,41}$

Several intermediates within or activated by the postreceptor insulin signalling pathways exert a negative feedback by phosphorylating serine residues on the $\beta$ subunit and IRS proteins (eg, protein kinase C-theta and the mammalian target of rapamycin). Attempts to interrupt this feedback have not been sufficiently selective. Provision of substrates for individual steps in the post-receptor pathways (eg, administration of the chiroinositol analogue pinitol enables signalling through phosphatidylinositol 3-kinase) is another approach under investigation. ${ }^{10}$

\section{Sodium-glucose co-transporter inhibitors}

Inhibitors of sodium-glucose co-transporters (eg, canagliflozin, dapagliflozin, and empagliflozin) are mainly directed against SGLT2 (also known as SLC5A2), which is located in the initial part of the proximal tubules and is responsible for reabsorption of about $90 \%$ of filtered glucose. Inhibition of SGLT2 causes excess glucose to be eliminated in the urine, which enables insulin-independent lowering of glucose, and lowering of bodyweight and blood pressure. ${ }^{42}$ Several further SGLT2selective inhibitors are advanced in development, all offering similar efficacy in clinical trials. ${ }^{43}$

Sotagliflozin strongly inhibits both SGLT2 and SGLT1 (also known as SLC5A1) and has also shown similar

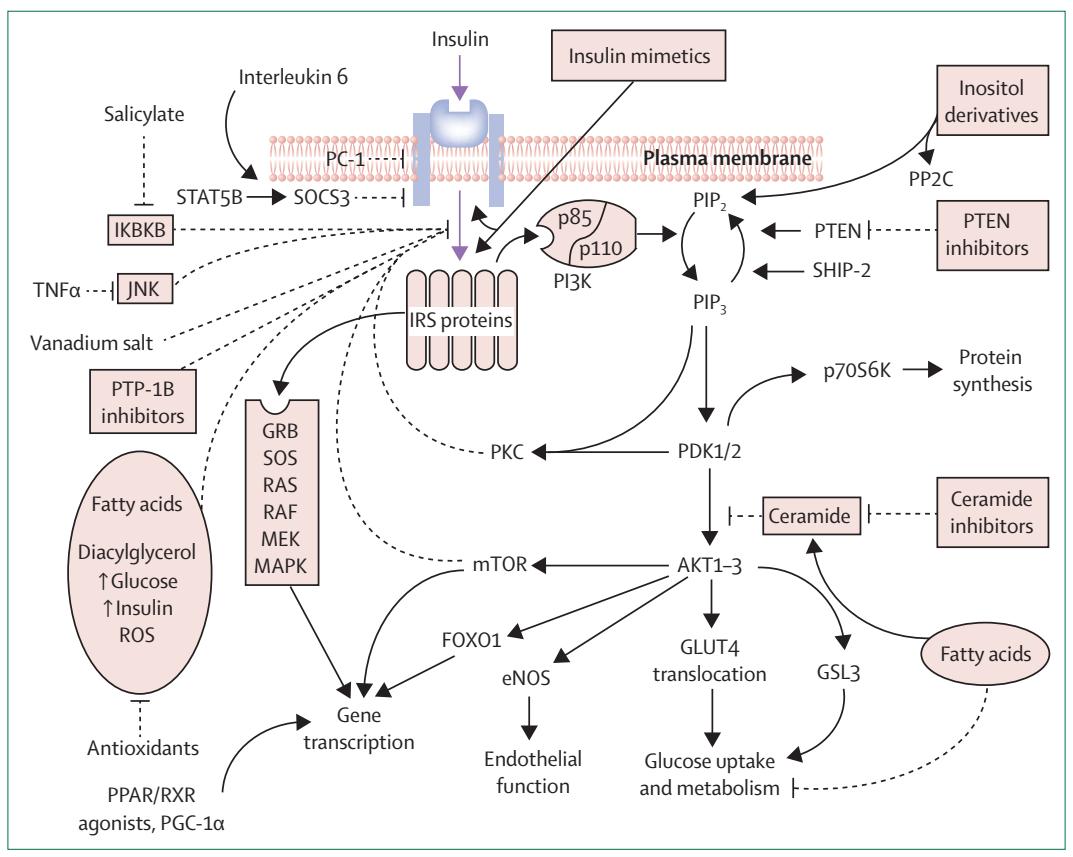

Figure 3: Pathways of intracellular insulin signalling showing some of the potential sites for therapeutic intervention 7.8

Dotted lines=inhibition. Solid lines=activation. Some agents listed in this figure are not discussed in this up-date and the reader is referred to references 7 and 8 . AKT=protein kinase B. AMPK=adenosine monophosphate-activated protein kinase. eNOS=endothelial nitric oxide synthase. FOXO1=forkhead box protein O1A. GLUT=glucose transporter isoform. $\mathrm{GRB}=$ growth factor receptor binding protein. $\mathrm{GSK3}=$ glycogen synthase kinase 3 . IKBKB=inhibitor kappa-B kinase- $\beta$. IRS=insulin receptor substrate. JNK=c-Jun $\mathrm{N}$-terminal kinase. MAPK=mitogen-activated protein kinase. $M E K=$ mitogen-activated protein kinase kinase. $m T O R=$ mammalian target of rapamycin. $P C-1=$ glycoprotein- 1 . PDK=phosphoinositide-dependent protein kinase. PGC-1 $\alpha=$ PPAR co-activator-1 $\alpha$ (also known as PPARGC1A). $\mathrm{PI} 3 \mathrm{~K}=$ phosphatidylinositol 3-kinase. $\mathrm{PIP}_{2}=$ phosphatidylinositol-3,4-bisphosphate. $\mathrm{PIP}_{3}=$ phosphatidylinositol-3,4,5trisphosphate. $\mathrm{PKC}=$ protein kinase $\mathrm{C}$. $\mathrm{PPAR}=$ peroxisome proliferator-activated receptor. $\mathrm{PP} 2 \mathrm{C}=$ protein phosphatase 2C. PTEN=phosphatase and tensin homologue. PTP-1B=protein tyrosine phosphatase-1B (also known as PTPN1). $\mathrm{RAF}=$ a serine-threonine protein kinase. $\mathrm{RAS}=$ a guanosine triphosphatase. $\mathrm{ROS}=$ reactive oxygen species. $\mathrm{RXR}=$ retinoid $X$ receptor. SHIP-2=src homology-2-inositol phosphatase (also known as INPPL1). SOCS3=suppressor of cytokine signalling 3. SOS=SOS Ras/Rac guanine nucleotide exchange factor. STAT5B=signal transducer and activator of transcription 5B. TNF $\alpha=$ tumour necrosis factor $\alpha$. 
efficacy to other SGLT2 inhibitors in initial clinical studies. ${ }^{44}$ SGLT1 mediates glucose absorption from the small intestine and contributes to the reabsorption of about $10 \%$ of filtered glucose by the kidney. Pharmacokinetic properties of this dual SGLT inhibitor suggest that it can defer intestinal glucose absorption more distally without causing malabsorption and might also increase the glucosuric effect. Sotagliflozin is now in phase 3 trials. ${ }^{45}$ SGLT inhibitors that mainly inhibit SGLT1 are under investigation in phase $1 .^{46}$

\section{Adipokine-based treatments}

In addition to facilitating weight loss through centrally mediated satiety and thermogenic effects, leptin exerts direct peripheral effects to improve insulin action and suppress glucagon. However, the glucose-lowering efficacy of leptin and leptin analogues was nominal during phase 3 trials in obese patients with type 2 diabetes, and benefits might only occur in individuals who are severely leptin deficient. ${ }^{47}$

Concentrations of another adipocyte hormone, adiponectin, are typically low in patients with type 2 diabetes, especially in the overweight, and adiponectin is known to exert several potentially beneficial effects including improved insulin sensitivity, improved endothelial function, and an anti-inflammatory effect. ${ }^{48,49}$ Orally active small-molecule agonists of the adiponectin receptors, ADIPOR1 and ADIPOR2, have been shown to improve glycaemic control and prolong lifespan in insulin resistant diabetic animals, raising expectations for clinical studies. ${ }^{48,49}$

Preliminary data suggest that other treatments based on adipocyte hormones could be applied to type 2 diabetes. For example, resistin reduces insulin sensitivity, increases proinflammatory cytokines, and adversely affects vascular function, whereas immunoneutralisation of resistin has improved insulin sensitivity in rodents. ${ }^{50}$ Increased concentrations of the retinol-binding protein 4 (RBP4), which transports plasma retinoids, have been detected early in the development of insulin resistance, and interventions that reduce RBP4 have increased insulin sensitivity in animals..$^{51}$

Fibroblast growth factor 21 (FGF21) is a peptide secreted by adipose tissue, liver, and muscle, which promotes fatty acid oxidation and hepatic gluconeogenesis during starvation. Plasma concentrations of FGF21 are raised in obesity and type 2 diabetes, possibly due to FGF21 resistance, and preliminary animal and human studies suggest that administration of FGF21 analogues can improve the lipid profile, reduce insulin resistance, and assist glucose-lowering, partly through increased production of adiponectin..$^{52,53}$

\section{Selective peroxisome proliferator-activated receptor modulators}

The nuclear peroxisome proliferator-activated receptor (PPAR) family offers a selection of potentially beneficial therapeutic effects but accompanying side-effects need to be minimised. PPAR $\gamma$ improves insulin sensitivity, glycaemic control, and various markers of vascular health while reducing inflammation, but also increases fluid retention and risk of heart failure, reduces bone mineral density, and often causes excessive adipogenesis. ${ }^{54}$ PPAR $\alpha$ improves the lipid profile, reduces inflammation, and seems to benefit microvascular complications, but might raise creatinine and risk of myopathological abnormalities, ${ }^{54}$ whereas PPAR $\delta$ counters weight gain through increased thermogenic energy expenditure, but long-term safety in man is not established..$^{54}$ Agents that selectively activate PPAR $\gamma$ and PPAR $\alpha$ (dual PPAR $\alpha / \gamma$ agonists, or glitazars), and triple PPAR agonists that also activate PPAR (known as panPPARs) have not been introduced for routine clinical use due to side-effects. ${ }^{54}$ Attention is directed to more selective PPAR modulators (SPPARMs) designed to capture desired effects and minimise unwanted effects. ${ }^{55}$ For example, addition of a nonthiazolidinedione SPPARM, INT131, showed similar glucose-lowering efficacy to pioglitazone but with less oedema and less weight gain during a phase 2A, 24-week randomised double-blind study ${ }^{56}$ in patients with type 2 diabetes receiving a sulfonylurea with or without metformin.

\section{Inhibitors of $11 \beta$-hydroxysteroid dehydrogenase 1}

Inhibitors of $11 \beta$-hydroxysteroid dehydrogenase 1 (11ßHSD1) reduce the production of active cortisol from cortisone. ${ }^{57}$ Such an inhibitor, INCB13739, improved insulin sensitivity, reduced $\mathrm{HbA}_{1 \mathrm{c}}$ by $0.6 \%$ (6 $\mathrm{mmol} /$ $\mathrm{mol})$, improved the lipid profile and reduced bodyweight during a 12-week randomised phase 2 double blind placebo controlled study ${ }^{58}$ in metformin-treated type 2 diabetes subjects. However, the efficacy achieved with $11 \beta$ HSD1 inhibitors has been low and although these agents should theoretically restrict cortisol production within the liver and adipose tissue, a reduction of circulating cortisol can occur and cause a compensatory increase in adrenocorticotropic hormone. ${ }^{59}$

\section{Agents that directly affect glucose production or metabolism}

Many compounds have been shown to reduce blood glucose in diabetic animals by suppressing hepatic glucose production, but few have progressed in clinical development. ${ }^{60}$ High risk of hypoglycaemia has been a limitation as noted with glucose-6-phosphatase inhibitors, ${ }^{60}$ because these agents inhibit the last step in gluconeogenesis and glycogenolysis. The risk of hypoglycaemia might be lessened with inhibitors of fructose-1,6 bisphosphatase, which create a compensatory increase in glycogenolysis, and some phase 2 clinical studies are in progress. ${ }^{61}$

Activation of adenosine monophosphate-activated protein kinase (AMPK), which is one of the cellular 
mechanisms of metformin and adiponectin, reduces blood glucose by increasing peripheral glucose uptake and increasing the metabolism of glucose and fatty acids. AMP is the main cellular activator of AMPK, and analogues of AMP are being explored as potential treatments. ${ }^{62}$

\section{Epigenetics, genetics, and proteomics}

The epigenetic approach is shown by sirtuins, which are nicotinamide-adenine-dinucleotide-dependent deacetylases and ADP ribosyltransferases that change gene transcription through chromatin silencing. Several small molecule sirtuin activators have produced effects similar to chronic caloric restriction in animal models. These effects include mitochondrial biogenesis and thermogenesis, glucose lowering, and improved vascular function, prompting continuing investigations into potential applications to treat obesity, diabetes, and cardiovascular disease. ${ }^{63,64}$

Genetic and proteomic studies continue to inform on the multivariable causes and pathogenesis of type 2 diabetes and identify specific treatment targets for a few patients, but for most patients these approaches have yet to inform the design of new drugs. ${ }^{65-67}$

\section{Antiobesity drugs}

Drugs approved for weight loss can assist glycaemic control in overweight and obese patients with type 2 diabetes. These products include the established intestinal lipase inhibitor orlistat and several newly approved satietyinducing drugs, notably a high dose GLP1 receptor agonist (liraglutide), a 5HT2c serotonin receptor agonist (lorcaserin), a phentermine-topiramate combination, and a bupropion-naltrexone combination. ${ }^{68-70}$ Further potential weight-lowering drugs, mostly based on intestinal satiety hormones, are in early development. ${ }^{70}$

\section{Insulins}

Advances in insulin treatment for patients with type 2 diabetes are beyond the remit of this Review, and have been reviewed recently. ${ }^{71}$ Key developments for the immediate future include biosimilar insulins, notably biosimilar glargine and lispro, and the introduction of more concentrated U200-U500 formulations of existing insulins. Clinical assessment of an ultra-fast short-acting formulation of insulin aspart and a long-acting formulation of lispro are advancing in development. An inhaled insulin (afrezza) has received little use since its launch in the USA in 2015: a buccal spray insulin is now available in some countries, and closed-circuit insulinglucagon pumps and other artificial pancreas devices are advancing in development. Delivery of insulin through skin patches or oral insulin formulations continue to be developed, and so-called smart insulins, which are activated or released from subcutaneous or circulating depots or skin patches in response to rising glucose concentrations, are giving encouraging results in preclinical studies. $^{72}$

\section{Safety issues}

Safety is particularly relevant yet difficult to assess for glucose-lowering treatments in view of their long-term use in patients with comorbidities. ${ }^{73}$ Cardiovascular risk is substantially raised in patients with type 2 diabetes and the US Food and Drug Administration (FDA) requires a meta-analysis of all cardiovascular events in phase 2 and 3 trials as part of any application for a new glucose-lowering treatment. ${ }^{74,75}$ The FDA has also requested or encouraged extensive post-marketing randomised controlled cardiovascular safety studies with composite endpoints that include cardiovascular deaths and non-fatal myocardial infarction and stroke (table 2). The studies completed so far with saxagliptin (SAVOR-TIMI), ${ }^{76}$ alogliptin (EXAMINE), ${ }^{77}$ sitagliptin $(\mathrm{TECOS}),{ }^{78}$ and lixisenatide (ELIXA) ${ }^{79}$ have reassuringly confirmed no adverse composite cardiovascular outcomes, and empagliflozin (EMPA-REG) ${ }^{80}$ has reported a significant $14 \%$ reduction in its composite cardiovascular outcome. ${ }^{80}$ During these studies other safety issues were being monitored including acute pancreatitis, bone fractures, infections, and cancers, and no significant increases in these adverse events have been reported to date. Although future drugs will ideally give positive outcomes in long-term cardiovascular safety trials, outcomes will vary with the numbers of different cardiovascular diseases, the duration of the study, and other variables across the different trial populations studied. Thus, the question arises as to whether heavy investment into large postmarketing cardiovascular outcome studies for new diabetes drugs could be compromising endeavours in innovative research.

\begin{tabular}{|c|c|c|c|c|c|c|}
\hline & Drug & $\begin{array}{l}\text { Start } \\
\text { date }\end{array}$ & End date & $\begin{array}{l}\text { Mean or } \\
\text { median } \\
\text { duration } \\
\text { (years) }\end{array}$ & n & $\begin{array}{l}\text { Primary } \\
\text { endpoint }\end{array}$ \\
\hline EXAMINE* & Alogliptin & 2009 & 2014 & 1.5 & 5380 & 3-pt MACE \\
\hline SAVOR-TIMI 53* & Saxagliptin & 2010 & 2014 & $2 \cdot 1$ & 16492 & 3-pt MACE \\
\hline TECOS* & Sitagliptin & 2008 & 2015 & $2 \cdot 8$ & 14671 & 4-pt MACE \\
\hline ELIXA* & Lixisenatide & 2010 & 2015 & $\sim 4 \cdot 0$ & 6075 & 4-pt MACE \\
\hline EMPA-REG* & Empagliflozin & 2010 & 2015 & $3 \cdot 1$ & 7020 & 3-pt MACE \\
\hline LEADER & Liraglutide & 2010 & 2016 & $\sim 5 \cdot 0$ & 9340 & 3-pt MACE \\
\hline CANVAS & Canagliflozin & 2009 & 2017 & $\sim 4 \cdot 0$ & 4407 & 3-pt MACE \\
\hline EXSCEL & Exenatide QW & 2010 & 2018 & $\sim 5.5$ & 14000 & 3-pt MACE \\
\hline CAROLINA & Linagliptin & 2010 & 2018 & $\sim 8.0$ & 6000 & 4-pt MACE \\
\hline CARMELINA & Linagliptin & 2013 & 2018 & $\sim 4 \cdot 0$ & 8300 & 4-pt MACE \\
\hline DECLARE-TIMI 58 & Dapagliflozin & 2013 & 2019 & $\sim 6 \cdot 0$ & 17150 & 3-pt MACE \\
\hline REWIND & Dulaglutide & 2011 & 2019 & $\sim 6.5$ & 9600 & 3-pt MACE \\
\hline ACE & Acarbose & 2009 & $?$ & $\sim 4 \cdot 0$ & $\sim 700$ & 3-pt MACE \\
\hline \multicolumn{7}{|c|}{$\begin{array}{l}\text { MACE=major adverse cardiovascular event. } 3 \text { point } \mathrm{MACE}=\text { composite of cardiovascular death and non-fatal } \\
\text { myocardial infarction and stroke. } 4 \text { point } \mathrm{MACE}=3 \text { point } \mathrm{MACE} \text { plus hospitalisation for another specified cardiovascular } \\
\text { event (eg, angina, heart failure). * Studies for which results have already been reported. }\end{array}$} \\
\hline
\end{tabular}




\section{Search strategy and selection criteria}

We searched MEDLINE, PubMed, and Google Scholar for original articles and reviews from January, 2011, to December, 2015, for full text papers in English on the treatment of hyperglycaemia. The main search terms were "hyperglycaemia", "diabetes", "obesity", "glucose lowering", "antidiabetes", "incretin" alone and with "therapy", "treatment", or "control".

\section{Conclusion}

Glycaemic control is crucial to the successful management of type 2 diabetes, but despite the variety of differently acting glucose-lowering drugs available, reversing the disease process and reinstatement of normal glucose homoeostasis is rarely possible. The need for multiple treatments has given rise to many new fixed-dose combinations of existing agents and further fixed-dose combinations are envisaged.$^{81}$ Innovative approaches with preclinical proof of concept include fatty acid receptor agonists and other novel interventions to promote $\beta$-cell function, chimeric designer peptides with pancreatic, satiety and thermogenic effects, small molecules to activate GLP1 receptors and potentiate insulin receptor $\beta$-subunit signalling, adipokine-based agents such as adiponectin receptor agonists, and AMPK activators. Many compounds have progressed into clinical studies and an analysis of ClinicalTrials.gov in February, 2014, has identified 180 trials registered for drugs to treat diabetes and its complications. ${ }^{82}$ However, most of the drugs that are advanced in development are different formulations of existing drugs or new members of existing classes with modest pharmacokinetic modifications. Entirely new interventions to address the underlying aetiopathogenic lesions of type 2 diabetes remain elusive.

\section{Contributors}

All authors contributed to all aspects of this work.

\section{Declaration of interests}

AAT received grants from National Institute for Health Research and Novo Nordisk Research Foundation, personal fees from Novo Nordisk, Lilly, BI, and BMS, and grants from Sanofi Excellence in Diabetes, outside this Review. CJB received grants and personal fees from AZ/ BMS,Sanofi, and personal fees from BI/Lilly, J\&J, MSD, Novo, Elcelyx, Poxel, outside this Review. AHB received personal fees from Merck Sharp \& Dohme, Novartis, AstraZeneca, Janssen, Takeda, Sanofi, Eli Lilly, and Novo Nordisk, outside this Review.

\section{Acknowledgments}

AAT is supported by the National Institute for Health Research (NIHR) in the UK. The views expressed in this publication are those of the authors and not necessarily those of the UK National Health Service, the NIHR, or the Department of Health.

\section{References}

1 American Diabetes Association Position Statement. Standards of medical care in diabetes-2015. Diabetes Care 2015; 38 (suppl 1): S1-93.

2 Inzucchi SE, Bergenstal RM, Buse JB, et al. Management of hyperglycemia in type 2 diabetes, 2015: a patient-centered approach: update to a position statement of the American Diabetes Association and the European Association for the Study of Diabetes. Diabetes Care 2015; 38: 140-49.
3 Handelsman Y, Bloomgarden ZT, Grunberger G, et al. American association of clinical endocrinologists and American college of endocrinology — clinical practice guidelines for developing a diabetes mellitus comprehensive care plan-2015. Endocr Pract 2015; 21 (suppl 1): 1-87.

4 de Pablos-Velasco P, Parhofer KG, Bradley C, et al. Current level of glycaemic control and its associated factors in patients with type 2 diabetes across Europe: data from the PANORAMA study. Clin Endocrinol (Oxf) 2014; 80: 47-56.

5 Defronzo RA. Banting lecture. From the triumvirate to the ominous octet: a new paradigm for the treatment of type 2 diabetes mellitus. Diabetes 2009; 58: 773-95.

6 Home P, Riddle M, Cefalu WT, et al. Insulin therapy in people with type 2 diabetes: opportunities and challenges? Diabetes Care 2014; 37: 1499-508.

7 Tahrani AA, Bailey CJ, Del Prato S, Barnett AH. Management of type 2 diabetes: new and future developments in treatment. Lancet 2011; 378: 182-97.

8 Bailey CJ. The current drug treatment landscape for diabetes and perspectives for the future. Clin Pharmacol Ther 2015; 98: 170-84.

9 Kahn SE, Cooper ME, Del Prato S. Pathophysiology and treatment of type 2 diabetes: perspectives on the past, present, and future. Lancet 2014; 383: 1068-83.

10 Bailey CJ. New drugs for the treatment of diabetes mellitus. In: DeFronzo RA, Ferrannini E, Zimmet P, Alberti GMM, eds. International Textbook of Diabetes Mellitus, 4th edn. Chichester: Wiley Blackwell, 2015: 709-25.

11 Nakamura A, Terauchi Y. Present status of clinical deployment of glucokinase activators. J Diabetes Investig 2015; 6: 124-32.

12 Rees MG, Gloyn AL. Small molecular glucokinase activators: has another new anti-diabetic therapeutic lost favour? Br J Pharmacol 2013; 168: 335-38.

13 Erion DM, Lapworth A, Amor PA, et al. The hepatoselective glucokinase activator PF-04991532 ameliorates hyperglycemia without causing hepatic steatosis in diabetic rats. PLoS One 2014; 9: e97139.

14 Mancini AD, Poitout V. GPR40 agonists for the treatment of type 2 diabetes: life after 'TAKing' a hit. Diabetes Obes Metab 2015; 17: 622-29.

15 Ohishi T, Yoshida S. The therapeutic potential of GPR119 agonists for type 2 diabetes. Expert Opin Investig Drugs 2012; 21: 321-28.

16 Nunez DJ, Bush MA, Collins DA, et al. Gut hormone pharmacology of a novel GPR119 agonist (GSK1292263), metformin, and sitagliptin in type 2 diabetes mellitus: results from two randomized studies. PLoS One 2014; 9: e92494.

17 Oh Y, Walenta E, Akiyama TE, et al. A Gpr120-selective agonist improves insulin resistance and chronic inflammation in obese mice. Nat Med 2014; 20: 942-47.

18 Pacini G, Mari A, Fouqueray P, Bolze S, Roden M. Imeglimin increases glucose-dependent insulin secretion and improves $\beta$-cell function in patients with type 2 diabetes. Diabetes Obes Metab 2015; 17: 541-45.

19 Meier JJ. GLP-1 receptor agonists for individualized treatment of type 2 diabetes mellitus. Nat Rev Endocrinol 2012; 8: 728-42.

20 Henry RR, Rosenstock J, Logan D, Alessi T, Luskey K, Baron MA. Continuous subcutaneous delivery of exenatide via ITCA 650 leads to sustained glycemic control and weight loss for 48 weeks in metformin-treated subjects with type 2 diabetes. J Diabetes Complications 2014; 28: 393-98.

21 Novo Nordisk press release. Bagsværd, Denmark, Feb 20, 2015. http://www.novonordisk.com/bin/getPDF.1896081.pdf (accessed Nov 9, 2015).

22 Kwon K-C, Nityanandam R, New JS, Daniell H. Oral delivery of bioencapsulated exendin-4 expressed in chloroplasts lowers blood glucose level in mice and stimulates insulin secretion in beta-TC6 cells. Plant Biotechnol J 2013; 11: 77-86.

23 Willard FS, Bueno AB, Sloop KW. Small molecule drug discovery at the glucagon-like peptide-1 receptor. Exp Diabetes Res 2012; 2012: 709893.

24 Cahn A, Raz I. Emerging gliptins for type 2 diabetes. Expert Opin Emerg Drugs 2013; 18: 245-58.

25 Sheu WH, Gantz I, Chen M, et al. Safety and efficacy of omarigliptin (MK-3102), a novel once-weekly DPP-4 Inhibitor for the treatment of patients with type 2 diabetes. Diabetes Care 2015; 38: 2106-14. 
26 Duan $H$, Ning M, Zou Q, et al. Discovery of intestinal targeted TGR 5 agonists for the treatment of type 2 diabetes. J Med Chem 2015; 58: 3315-28.

27 Gough SC, Bode BW, Woo VC, et al. One-year efficacy and safety of a fixed combination of insulin degludec and liraglutide in patients with type 2 diabetes: results of a 26-week extension to a 26-week main trial. Diabetes Obes Metab 2015; 17: 965-73.

28 Rosenstock J, Diamant M, Silvestre L et al. Benefits of a fixed ratio formulation of once daily insulin glargine/lixisenatide (Lixilan) versus glargine in type 2 diabetes (T2DM) inadequately controlled with metformin. Diabetes 2014; 63 (suppl 1): P87-88.

29 Fosgerau K, Hoffmann T. Peptide therapeutics: current status and future directions. Drug Discov Today 2015; 20: 122-28.

30 Sadry SA, Drucker DJ. Emerging combinatorial hormone therapies for the treatment of obesity and T2DM. Nat Rev Endocrinol 2013; 9: 425-33.

31 Gault VA, Bhat VK, Irwin N, Flatt PR. A novel glucagon-like peptide-1 (GLP-1)/glucagon hybrid peptide with triple-acting agonist activity at glucose-dependent insulinotropic polypeptide, GLP-1, and glucagon receptors and therapeutic potential in high fat-fed mice. J Biol Chem 2013; 288: 35581-91.

32 Finan B, Yang B, Ottaway N, et al. A rationally designed monomeric peptide triagonist corrects obesity and diabetes in rodents. Nat Med 2015; 21: 27-36.

33 Sammons MF, Lee ECY. Recent progress in the development of small-molecule glucagon receptor antagonists. Bioorg Med Chem Lett 2015; 25: 4057-64.

34 Kelly RP, Garhyan P, Raddad E, et al. Short-term administration of the glucagon receptor antagonist LY2409021 lowers blood glucose in healthy people and in those with type 2 diabetes. Diabetes Obes Metab 2015; 17: 414-22.

35 Filipski KJ. Small molecule glucagon receptor antagonists: a patent review (2011-2014). Expert Opin Ther Pat 2015; 25: 819-30.

36 Menting JG, Whittaker J, Margetts MB, et al. How insulin engages its primary binding site on the insulin receptor. Nature 2013; 493: 241-45.

37 Bhaskar V, Goldfine ID, Bedinger DH, et al. A fully human, allosteric monoclonal antibody that activates the insulin receptor and improves glycemic control. Diabetes 2012; 61: 1263-71.

38 Webster NJ, Park K, Pirrung MC. Signaling effects of demethylasterriquinone B1, a selective insulin receptor modulator. ChemBioChem 2003; 4: 379-85.

39 Nankar RP, Doble M. Non-peptidyl insulin mimetics as a potential antidiabetic agent. Drug Discov Today 2013; 18: 748-55.

40 Koren S, Fantus IG. Inhibition of the protein tyrosine phosphatase PTP1B: potential therapy for obesity, insulin resistance and type-2 diabetes mellitus. Best Pract Res Clin Endocrinol Metab 2007; 21: $621-40$

41 Popov D. Novel protein tyrosine phosphatase 1B inhibitors: interaction requirements for improved intracellular efficacy in type 2 diabetes mellitus and obesity control. Biochem Biophys Res Commun 2011; 410: 377-81.

42 Tahrani AA, Barnett AH, Bailey CJ. SGLT inhibitors in management of diabetes. Lancet Diabetes Endocrinol 2013; 1: 140-51.

43 Nauck MA. Update on developments with SGLT2 inhibitors in the management of type 2 diabetes. Drug Des Devel Ther 2014; 8: 1335-80.

44 Lampueta P, Zambrowicz B, Strumph P, Sands A. Development of sotagliflozin, a dual sodium-dependent glucose transporter $1 / 2$ inhibitor. Diabetes Vas Dis Res 2015; 12: 101-10.

45 Zambrowicz B, Freiman J, Brown PM, et al. LX4211, a dual SGLT1/ SGLT2 inhibitor, improved glycemic control in patients with type 2 diabetes in a randomized, placebo-controlled trial. Clin Pharmacol Ther 2012; 92: 158-69.

46 Dobbins RL, Greenway FL, Chen L et al. Selective sodium dependent glucose transporter 1 inhibitors block glucose absorption and impair glucose-dependent insulinotropic peptide release. Am J Physiol Gastrointest Liver Physiol 2015; 308: G946-54.

47 Coppari R, Bjørbæk C. Leptin revisited: its mechanism of action and potential for treating diabetes. Nat Rev Drug Discov 2012; 11: 692-708.

48 Fisman EZ, Tenenbaum A. Adiponectin: a manifold therapeutic target for metabolic syndrome, diabetes, and coronary disease? Cardiovasc Diabetol 2014; 13: 103-09.
49 Okada-Iwabu M, Yamauchi T, Iwabu M, et al. A small-molecule AdipoR agonist for type 2 diabetes and short life in obesity. Nature 2013; 503: 493-99.

50 Jamaluddin MS, Weakley SM, Yao Q, Chen C. Resistin: functional roles and therapeutic considerations for cardiovascular disease. Br J Pharmacol 2012; 165: 622-32.

51 Zemany L, Bhanot S, Peroni OD, et al. Transthyretin antisense oligonucleotides lower circulating RBP4 levels and improve insulin sensitivity in obese mice. Diabetes 2015; 64: 1603-14.

52 Gaich G, Chien JY, Fu H, et al. The effects of LY2405319, an FGF21 analog, in obese human subjects with type 2 diabetes. Cell Metab 2013; 18: 333-40.

53 Lin Z, Tian H, Lam KS, et al. Adiponectin mediates the metabolic effects of FGF21 on glucose homeostasis and insulin sensitivity in mice. Cell Metab 2013; 17: 779-89.

54 Gross B, Staels B. PPAR agonists: multimodal drugs for the treatment of type 2 diabetes. Clin Endocrinol Metab 2007; 21: 687710.

55 Sahebkar A, Chew GT, Watts GF. New peroxisome proliferatoractivated receptor agonists: potential treatments for atherogenic dyslipidemia and non-alcoholic fatty liver disease. Expert Opin Pharmacother 2014; 15: 493-503.

56 DePaoli AM, Higgins LS, Henry RR, Mantzoros C, Dunn FL, and the INT131-007 Study Group. Can a selective PPAR $\gamma$ modulator improve glycemic control in patients with type 2 diabetes with fewer side effects compared with pioglitazone? Diabetes Care 2014; 37: 1918-23.

57 Anderson A, Walker BR. 11ß-HSD1 inhibitors for the treatment of type 2 diabetes and cardiovascular disease. Drugs 2013; 73: 1385-93.

58 Rosenstock J, Banarer S, Fonseca VA, et al, and the INCB13739-202 Principal Investigators. The 11-beta-hydroxysteroid dehydrogenase type 1 inhibitor INCB13739 improves hyperglycemia in patients with type 2 diabetes inadequately controlled by metformin monotherapy. Diabetes Care 2010; 33: 1516-22.

59 Heise T, Morrow L, Hompesch M, et al. Safety, efficacy and weight effect of two 11ß-HSD1 inhibitors in metformin-treated patients with type 2 diabetes. Diabetes Obes Metab 2014; 16: 1070-77.

60 Agius L. New hepatic targets for glycaemic control in diabetes. Best Pract Res Clin Endocrinol Metab 2007; 21: 587-605.

61 van Poelje PD, Potter SC, Erion MD. Fructose-1, 6-bisphosphatase inhibitors for reducing excessive endogenous glucose production in type 2 diabetes. Handbook Exp Pharmacol 2011; 203: 279-301.

62 Coughlan KA, Valentine RJ, Ruderman NB, Saha AK. AMPK activation: a therapeutic target for type 2 diabetes? Diabetes Metab Syndr Obes 2014; 7: 241-53.

63 Chalkiadaki A, Guarente L. Sirtuins mediate mammalian metabolic responses to nutrient availability. Nat Rev Endocrinol 2012; 8: 287-96.

64 Cao Y, Jiang X, Ma H, et al. SIRT1 and insulin resistance. J Diabetes Complications 2015; published online Sept 2. DOI:10.1016/j.jdiacomp.2015.08.022.

65 Dorajoo R, Liu J, Boehm BO. Genetics of type 2 diabetes and clinical utility. Genes (Basel) 2015; 6: 372-84.

66 Topf F, Schvartz D, Gaudet P, et al. The Human Diabetes Proteome Project (HDPP): from network biology to targets for therapies and prevention. Adv Intern Med 2013; 1: 3-11.

67 López-Villar E, Martos-Moreno GA, Chowen JA, Okada S, Kopchick JJ, Argente J. A proteomic approach to obesity and type 2 diabetes. J Cell Mol Med 2015; 19: 1455-70.

68 Aldekhail NM, Logue J, McLoone P, Morrison DS. Effect of orlistat on glycaemic control in overweight and obese patients with type 2 diabetes mellitus: a systematic review and meta-analysis of randomized controlled trials. Obes Rev 2015; 16: 1071-80.

69 Davies MJ, Bergenstal R, Bode B, et al, and the NN8022-1922 Study Group. Efficacy of liraglutide for weight loss among patients with type 2 diabetes: The SCALE Diabetes Randomized Clinical Trial. JAMA 2015; 314: 687-99.

70 Scheen AJ, Van Gaal LF. Combating the dual burden: therapeutic targeting of common pathways in obesity and type 2 diabetes. Lancet Diabetes Endocrinol 2014; 2: 911-22.

71 Cahn A, Miccoli R, Dardano A, Del Prato S. New forms of insulin and insulin therapies for the treatment of type 2 diabetes. Lancet Diabetes Endocrinol 2015; 3: 638-52. 


\section{Review}

72 Veiseh O, Langer R. Diabetes: a smart insulin patch. Nature 2015; 524: 39-40.

73 Bailey CJ. Safety of antidiabetes medications: an update. Clin Pharmacol Ther 2015; 98: 185-95.

74 Sarwar N, Gao P, Seshasai SR, et al, and the Emerging Risk Factors Collaboration. Diabetes mellitus, fasting blood glucose concentration, and risk of vascular disease: a collaborative meta-analysis of 102 prospective studies. Lancet 2010; 375: 2215-22.

75 FDA guidance for industry. Diabetes mellitus-evaluating cardiovascular risk in new antidiabetic therapies to treat type 2 diabetes. US Department of Health and Human Services, Food and Drug Administration Center for Drug Evaluation and Research (CDER). December 2008, 1-5. http://www.fda.gov/downloads/ Drugs/GuidanceComplianceRegulatoryInformation/Guidances/ ucm071627.pdf (accessed Nov 8, 2015).

76 Scirica BM, Bhatt DL, Braunwald E, et al, and the SAVOR-TIMI 53 Steering Committee and Investigators. Saxagliptin and cardiovascular outcomes in patients with type 2 diabetes mellitus. N Engl J Med 2013; 369: 1317-26.
77 White WB, Cannon CP, Heller SR, et al, and the EXAMINE Investigators. Alogliptin after acute coronary syndrome in patients with type 2 diabetes. N Engl J Med 2013; 369: 1327-35.

78 Green JB, Bethel MA, Armstrong PW, et al, and the TECOS Study Group. Effect of sitagliptin on cardiovascular outcomes in type 2 diabetes. N Engl J Med 2015; 373: 232-42.

79 Pfeffer MA, Claggett B, Diaz R, et al. Lixisenatide in patients with type 2 diabetes and acute coronary syndrome. N Engl J Med 2015; 373: 2247-57.

80 Zinman B, Wanner C, Lachin JM, et al. Empagliflozin, cardiovascular outcomes, and mortality in type 2 diabetes. N Engl J Med 2015; 373: 2117-28.

81 Blonde L, San Juan ZT, Bolton P. Fixed-dose combination therapy in type 2 diabetes mellitus. Endocr Pract 2014; 20: 1322-32.

82 Medicines in development. Diabetes. Report presented by America's Biopharmaceutical Research Companies. Pharmaceutica Research and Manufacturers of America, WA, USA, February 2014, pp 1-24. http://www.phrma.org/sites/default/files/pdf/ diabetes2014.pdf (accessed Nov 8, 2015). 